\title{
LA LEYENDA DORADA DEL PROTESTANTISMO. HERMENÉUTICA BÍBLICA, LIBERTAD DE CONCIENCIA Y LIBERTAD POLÍTICA*
}

\author{
POR \\ MARTA GARCÍA-ALONSO ${ }^{1}$ \\ UNED
}

\begin{abstract}
RESUMEN
Es común pensar que la Reforma y la modernidad política van de la mano, puesto que autores tan relevantes como Hegel, Tocqueville, Jellinek o Martha Nussbaum, en nuestros días, sitúan la religión protestante en el origen de ideas tan fundamentales como la libertad de conciencia y la libertad política. En este trabajo, nos proponemos analizar brevemente la relación entre libertad de conciencia y libertad política a través de dos figuras fundamentales de la tradición protestante calvinista: Juan Calvino - su fundador, artífice de su ortodoxia y su vía institucional- y Pierre Bayle, el filósofo de Rotterdam que llevó el calvinismo a su cota más alta de heterodoxia en el siglo XVII. Veremos de qué modo comprenden el acceso a la Escritura y cuál es la fórmula política que defienden para su contexto inmediato.
\end{abstract}

PALABRAS CLAVE: Reforma protestante; Calvino; Bayle; libertad de conciencia; libertad política.

\section{THE GOLDEN LEGEND OF PROTESTANTISM. BIBLICAL HERMENEUTICS, FREEDOM OF CONSCIENCE AND POLITICAL FREEDOM}

\begin{abstract}
It is usually assumed that political modernity and the Reformation go hand in hand. Authors such as Hegel, Tocqueville, Jellinek or Martha Nussbaum find in the Protestant Reformation the origin of ideas such as political freedom or freedom of conscience. In this paper, I will try to analyze the relationship between these two concepts in two fundamental characters in the Calvinist tradition. John Calvin, its founding father, on the one hand, and, on the other, Pierre Bayle, the Rotterdam philosopher who pushed Calvinism to its most heterodox forms in the XVII century. I will show how they both understand the interpretation of the Bible and the political arrangements that they defended for their close context.
\end{abstract}

KEY WORDS: Protestant Reformation; Calvin; Bayle; Freedom of conscience; Political freedom.

CÓMO CITAR ESTE ARTículo / CITATION: García-Alonso, M. 2018. «La leyenda dorada del protestantismo. Hermenéutica bíblica, libertad de conciencia y libertad política». Hispania Sacra 70, 141: 147-156. https://doi.org/10.3989/hs.2018.014

Recibido/Received 09-05-2017

Aceptado/Accepted 09-06-2017

\section{INTRODUCCIÓN}

Hace un par de años, ha visto la luz La sombra de la leyenda negra, dedicado a una de las discusiones más apasionantes de nuestra historia intelectual: ¿ha existido una

"Este trabajo fue previamente discutido en el Seminario llustración (Fundación Ortega Gasset y Marañón), dirigido por María José Villaverde. Agradezco a mis colegas del seminario sus comentarios y sugerencias. Agradezco, igualmente, los comentarios y sugerencias de los evaluadores.

1 mgalonso@fsof.uned.es / ORCID iD: http://orcid.org/0000-00027030-0450 leyenda negra sobre España o se trata de una interpretación victimista de nuestra historia? ¿Las interpretaciones que motivan esa famosa mala prensa de España son únicamente causadas por la envidia razonable que, desde Europa, se tiene a una potencia imperial o existen causas estructurales que permiten explicarla? ${ }^{2}$ Muchos de los grandes ilustrados vincularon

2 La introducción del libro, a cargo de María José Villaverde y Francisco Castilla hace un repaso exhaustivo por las diferentes teorías que, a lo largo de los siglos, se han ido elaborando en torno a este tópico: Castilla y Villaverde 2016: 11-98. 
decadencia económica con degeneración moral y regresión religiosa y, por esa razón, las plumas de los filósofos que fusionan llustración y modernidad, construirán una idea de Europa enfrentada al antimodelo que, desde entonces, vendrá representado por España, en pares de tópicos que aún funcionan hoy día: luz de la razón vs. oscurantismo medieval; ciencia moderna vs. escolástica; política liberal vs. despotismo; raza blanca pura vs. mestiza; religión protestante vs. católica... Y así, un largo etcétera. ${ }^{3}$ Lo que explica que, en paralelo a la leyenda negra española, se hubiera fraguado una fábula opuesta: la leyenda dorada de la Reforma. La modernidad será pensada, desde entonces, como protestante, blanca y liberal. Y uno de los periodos álgidos de esta articulación teórica será la época postrevolucionaria francesa, como señala Michael Pinty. ${ }^{4}$

En 1804 el Institut National de France propone un premio al ensayo histórico que responda mejor a la siguiente cuestión: ¿Cuál ha sido la influencia de la Reforma de Lutero en la política de los Estados europeos y en la llustración? El Instituto pretendía salvaguardar la herencia ilustrada que consideraba diametralmente opuesta a la tradición católica que el Concordato napoleónico de 1801 había restaurado en la Francia postrevolucionaria. El ensayo de Charles Villers, titulado Essai sur l'esprit et influence de la réformation de Luther, fue premiado, traducido al inglés y al alemán, además de conocer varias ediciones en su tiempo. En él, Villiers no habría hecho sino sintetizar discusiones y debates bien conocidos en Alemania, a decir d Pinty. Siguiendo a Karl Leonhard Reinhold, el autor francés defenderá que la revolución debía ser espiritual, no política: la Reforma habría cimentado una revolución religiosa y filosófica sin necesidad de violencia alguna, tan solo reivindicando la lectura individual de la Biblia y la libertad de conciencia. Dicho lo cual, Villers no deja de insistir en las consecuencias políticas positivas que trae consigo la adquisición de los principios evangélicos en los países protestantes:

Si por su calidad de jefe de la Iglesia y por la confianza que le otorgan los pueblos, un príncipe reformado adquirió mayor solidez y autoridad de la que antes tenía, la misma naturaleza del movimiento que le otorgaba tal autoridad de nuevo cuño entre las manos, le obligaba a usarla del modo más legítimo y equitativo [posible]. No adquiría fuerza sino para servir y defender la nación, y no para oprimirla. Los auditorios [observateurs] más cualificados han reconocido que la naturaleza ha hecho particularmente republicanos a los pueblos del norte; y no se puede negar que muchos de los que han abrazado la Reforma no estuvieron siempre animados por este espíritu, como los sajones, suizos, holandeses e ingleses: se puede decir que la Reforma, por sí misma, no ha sido, más que una aplicación [de ese espíritu]. Esta sacudida, a su vez, habría despertado toda la energía y las ideas que siguieron. En el fondo, la voluntad de ser libre en asuntos de conciencia es la misma que la voluntad de ser libre en asuntos civiles [...] $\mathrm{Ni}$ Prusia ni Dinamarca tienen parlamento, ni barrera visible alguna de la autoridad real y allí se disfruta de

3 Esta propaganda anti-española termina permeando en la élite intelectual de nuestro país. Entre 1823 y 1850, los intelectuales españoles asumen que modernidad y protestantismo son dos procesos que van indisolublemente de la mano. Cfr. Fernández Sebastián 2016: 483-510. En el mismo sentido, ibídem 2015: 166-175.

4 Pinty 2012: 303-329. la más admirable libertad; pues las barreras invisibles están en las almas, incluida en la del príncipe, alimentado y educado en el espíritu que anima la nación; están en las costumbres más nimias, aquellas más alejadas de todo fasto y orgullo. ${ }^{5}$

La tesis de Villers se habría nutrido, entre otras cosas, de la vinculación entre religión y modernidad elaborada por los intelectuales alemanes que presentan su tradición filosofía como paradigma de progreso, en continuidad directa con el espíritu de la Reforma. Tras Reinhold, Fichte defenderá que la Reforma constituye el agente más poderoso en la historia de la educación del pueblo alemán, hasta el punto de considerar a los reformadores como librepensadores. Es sabido que Hegel, por su parte, hizo de la Reforma el equivalente mismo de la modernidad y motor del desarrollo del espíritu. ${ }^{6}$ Asimismo, según Feuerbach, la Reforma habría protagonizado la liberación del hombre al humanizar a Dios, mediante la transformación de la teología en antropología, y poniendo a Cristo en el lugar que Dios ocupaba en la ontoteología medieval. A su vez, Nietzsche ensalzó a Lutero como uno de los momentos cumbre en la historia del pueblo alemán y le atribuyó la iniciativa en la creación de la lengua alemana. No obstante, a diferencia de sus compatriotas, consideró que la Reforma suponía un freno a la llustración, no un motor de la misma, por cuanto la vuelta a los valores primigenios del cristianismo promovida por el protestantismo, suponía la negación misma del proyecto ilustrado. ${ }^{7}$

No sería excesivo decir, por tanto, que la tesis de Villiers es un eco de las ideas que pueblan el imaginario común de su Alemania de acogida. Pero la estrecha relación que la filosofía alemana establece entre protestantismo e Ilustración, no se agota en su tradición cultural, sino que viaja a Estados Unidos, a través del vínculo que se establece entre libertad religiosa y derechos humanos. Ya Tocqueville en su libro De la démocratie en Amérique mantenía que el puritanismo era el verdadero fundamento de la democracia americana, por cuanto la libertad política es un resultado de las luchas religiosas. ${ }^{8}$ Y Georg Jellinek defendió que el libre examen protestante está en los orígenes de la libertad de conciencia, presente hoy en todas las constituciones modernas y las declaraciones de derechos. Según esto, no es en la Revolución Francesa sino en el protestantismo donde debemos buscar el origen de los derechos humanos y del ciudadano ${ }^{9}$, puesto que la libertad religiosa constituye la fuente de la toda capacidad de expresión legislativa. En su obra Declaración de los derechos del hombre y del ciudadano escribe:

La idea de consagrar legislativamente esos derechos naturales, inalienables e inviolables del individuo, no es de origen político, sino religioso. Lo que hasta aquí se ha recibido como una obra de la Revolución, es en realidad un fruto de la Reforma y de sus luchas. Su primer apóstol no es Lafayette, sino aquel Roger Williams que, Ilevado de su entusiasmo

\footnotetext{
5 Villers 1804: 35-36. Texto electrónico que reproduce la edición original de la obra. La traducción es nuestra.

6 «La evolución y el progreso del espíritu, desde la Reforma, consiste en esto: que el espíritu ahora, por la conciliación entre el ser humano y Dios, tiene conciencia de su libertad...» (Hegel 1989: 665).

7 Un análisis magnífico del desarrollo de esta reinterpretación de la Reforma en la tradición filosófica alemana puede leerse en Ginzo 2000. Asimismo, cfr. Gómez-Heras 1986.

8 Cfr. Tocqueville 2010: I, 2, 73.

9 Cfr. Jellinek 1980: 383 y ss.
} 
religioso, emigraba hacia las soledades, para fundar un imperio sobre la base de libertad de las creencias, y cuyo nombre los americanos aun hoy recuerdan con veneración. ${ }^{10}$

Para que la Declaración francesa tuviera lugar, dice Jellinek, tuvo que producirse previamente la americana, donde la influencia teórica más importante no fue Rousseau (como mantenían las tesis de su época), sino el protestantismo puritano americano del XVII y su defensa de la libertad religiosa. No obstante, según el autor, no debería perderse mucho tiempo en discutir dónde situar el origen de esa libertad religiosa, sino establecer quien la plasmó por primera vez en un texto jurídico y «eso ha tenido efecto, por primera vez, en la antigua Carta de Rhode Island de 1663 " ${ }^{11}$ Los ecos de sus palabras llegan hasta nuestros días, cuando la libertad de conciencia protestante es reivindicada como fundamento de la tolerancia moderna. Una de las muchas versiones de esta tesis se encuentra en un conocido opúsculo del politólogo alemán Iring Fetscher, donde leemos que la tolerancia es un logro de la ilustración burguesa, que habría extendido y llevado a la práctica aquellos principios que alumbraron la libertad en el ámbito de las religiones. ${ }^{12}$ De acuerdo con Fetscher, la idea de tolerancia solo pudo desarrollarse al disminuir la influencia política o pública de las religiones, con la secularización del Estado tras la Reforma protestante, de ahí que sean los principios enarbolados por los reformadores en su lucha contra Roma - ante todo, la libre interpretación de la Escritura conforme a la propia conciencia-, lo que habría propiciado la conversión de la esfera espiritual en un dominio privado, en el que los Estados carecen de competencias.

En esta misma línea, Martha Nussbaum ha propuesto una combinación entre estas dos hipótesis -el origen de la tolerancia y la paternidad de la libertad política - atribuida a los puritanos. Según Nussbaum, Robert Williams (16031683) sería el fundador de la moderna idea tolerancia, por su defensa de la libertad de conciencia ligada al respeto por la diferencia cultural, en la que se incluye la diversidad religiosa. ${ }^{13}$ Sin embargo, según Teresa Bejan, la idea de tolerancia de Williams en absoluto puede ser referida a las nociones contemporáneas de respeto mutuo o reivindicación de la diferencia. Que no esté permitido perseguir a nadie por motivos ideológicos - lo que pondría en cuestión la paz civil-, no significa que uno no pueda, al mismo tiempo, aborrecer, depreciar y oponerse a sus creencias. ${ }^{14}$ Para Williams, la conducta respetuosa que debemos a nuestros semejantes -el trato civilizado necesario en la convivencia social-, no tiene por qué incluir la aceptación de sus creencias, la tolerancia es un asunto civil, de convivencia política, no religioso:

Muchos barcos van al mar, con muchas almas por barco, cuyo bienestar, para lo bueno y para lo malo, es común. Y esta es la auténtica imagen de una República. Nunca he negado que, a pesar de esta libertad [de conciencia]... si cualquier marino rehúsa cumplir con su deber, o un pasajero a pagar su cargo,... si cualquiera rehusase obedecer a las leyes y órdenes del barco, sobre su preservación y pan común, si cualquiera predicase o

\footnotetext{
10 Cfr. Ibídem 2000: 107.

11 Ibídem: 154.

12 Fetscher 1995

13 Nussbaum 2008.

14 Bejan 2011: 409-420. Agradezco a J. C. Laursen la referencia.
}

escribiese que no debiera haber comandantes ni oficiales, porque todos somos iguales en Cristo... Nunca he negado [la libertad de conciencia], digo, pero en tales casos, comoquiera que se presentasen, el comandante o comandantes podría juzgar, resistir, obligar y castigar a los transgresores de acuerdo con sus méritos $y$ merecimientos. ${ }^{15}$

Hoy día no solo se discute la precisión histórica de muchas de las interpretaciones de los clásicos de la tradición reformada, como el de Nussbaum. Desde que George Williams publicara The Radical Reformation, dedicada a la influencia política de la tradición anabaptista, el interés por las figuras que no pertenecen a la línea institucional de la Reforma no ha hecho más que aumentar. Por ejemplo, Pocock ha puesto el acento en el papel de los arminianos en la llustración de los Países Bajos; Sheehan retoma la importancia de la relación entre hermenéutica bíblica e Ilustración; y Gillespie defiende que se debe interpretar la llustración a partir de las fuentes ontológicas de la tradición nominalista, en la que se inscribe la Reforma. ${ }^{16}$ De una manera o de otra, todos coinciden en señalar la crítica religiosa como el elemento definitorio de la modernidad y la llustración. ${ }^{17}$

Imposible analizar en un artículo toda la tradición protestante y sus teóricos, pues son enormemente variados y los contextos y tiempos hacen que muchas de las doctrinas originarias elaboradas por los primeros reformadores varíen considerablemente, como vemos en este volumen colectivo. En este trabajo, nos proponemos analizar brevemente la vinculación entre examen de la Escritura y libertad política. Y para ello, articularemos nuestro trabajo en torno a dos figuras fundamentales de la tradición calvinista: Juan Calvino - su fundador y artífice de su ortodoxia y su vía institucional- y Pierre Bayle, el filósofo de Rotterdam que llevó el calvinismo a su cota más alta de heterodoxia en el siglo XVII. Veremos de qué modo comprenden el acceso a la Escritura y cuál es la fórmula política que defienden para su contexto inmediato. Si libertad de examen (libre interpretación de la Biblia) y libertad política están estructuralmente ligadas al protestantismo, tal y como sostiene el tópico, ambos autores deberían servirnos para ilustrar dicha coordinación. Veremos que la cuestión es mucho más compleja.

\section{LOS PRIMEROS PASOS DE LA VÍA DEL EXAMEN}

El debate sobre el examen de la Escritura ha sido comúnmente identificado con el concepto de libre examen, como libertad individual del cristiano para interpretar y leer la Biblia. Uno de los teólogos más beligerantes sosteniendo esta tesis fue el cardenal Bellarmino, quien acusaba a los reformados de fiarse de su propio juicio, incluso de desviarlo en un sentido particular contrario al que tiene según la

15 Williams, "Letter to the Town of Providence, ca. Jan. 1654/5», citado en Bejan 2011: 416.

16 Pocock 1999; Sheehan 2005; y Gillespie 2008.

17 No obstante, Margaret Jacob considera que la modernidad política que se asienta en conceptos como pluralidad, consenso, discusión, representación o elecciones - por citar solo algunos - tienen su asidero en las prácticas de la masonería, no en la filosofía francesa materialista, ni en la tradición protestante: cfr. Jacob 1991: 15. Asimismo, Jacob 2003. 
Iglesia, única que puede interpretar las Escrituras. ${ }^{18}$ Ahora bien, es importante no confundir el rechazo protestante del magisterio de la Iglesia católica con la defensa de la interpretación subjetiva de la Biblia. Lo que la vía de examen reformado implicaba era una alternativa a la vía de autoridad eclesial que suponía una armonía preestablecida entre Escritura y magisterio católico, no el libre examen definido al modo de la teología liberal protestante del siglo XIX, según el cual cada fiel tenía el derecho de estudiar y examinar libremente la Biblia. ${ }^{19}$

A nuestro modo de ver, la doctrina del libre examen no debería ser aplicada anacrónicamente a los siglos precedentes pues, para Calvino - como para Lutero-, la vía del examen se aplica a la independencia de criterio del cristiano frente a la enseñanza de la Iglesia católica sobre la Biblia - los concilios, la tradición, los dogmas eclesiales-, no en defensa de la lectura individual de la Escritura. ${ }^{20}$ En este punto, los primeros reformadores defienden, precisamente, todo lo contrario: es la Biblia la que impone su interpretación al sujeto y no éste quien ha de darle sentido. ${ }^{21} Y$ es que para ellos no hay nada oscuro en la Escritura - al contrario que para sus adversarios católicos-,y si algo lo parece, se debe a la ceguera e ignorancia de los lectores, no a la falta de claridad del texto. ${ }^{22}$ Son las conclusiones resultantes de los fundamentos bíblicos las que se pueden discutir, no la revelación que han de ser equiparada a primeros principios (evidentes, claros), comienzo de toda demostración y, por tanto, origen de toda explicación. Ahora bien, para que la Biblia muestre como claras y distintas las verdades fundamentales referidas a la salvación -lo esencial de la religión-, es imprescindible que intervenga la claridad interna otorgada gratuita y selectivamente por el Espíritu santo a los elegidos. ${ }^{23}$ Por lo tanto, el examen precisa cualidades espirituales en el lector que van mucho más allá de su propia racionalidad y que, por eso mismo, no son

18 «loannes Calvinus -4. Institut. cap. $9 \S 8,12$ \& 13-Conciliorum etiam maxime generalium, definitiones ad amussim Scripturarum examinari iubet; proinde privatos homines iudices facit in causa fidei, non solum Patrum, sed etiam Conciliorum, nec ullum omnino relinquit Ecclesiae commune iudicium». (Cfr. Bellarmino 1610: vol. I, I. iii, c. 1, 178D-180C). Semejante fue, al parecer, la acusación que dirigió a Calvino el jesuita Pierre Coton (1564-1626) en su Genève plagiaire (1618): los particulares no pueden interpretar la Escritura. Más que por sus escritos contra el protestantismo, a Coton se le conoce como confesor de Henri IV y Louis XIII.

19 Para desarrollar lo que sigue, nos apoyamos en un trabajo anterior: García-Alonso 2008.

20 Calvino, IRC: IV, 8, 8. IRC: Calvin 1957-1963. Se cita libro, capítulo y página.

21 Assertio omnium articulorum: WA 7: 98. WA: Weimarer Ausgabe. Hemos utilizado la edición de O. Clemen (Lutero 1983).

22 Las palabras de Lutero no dejan duda (De servo arbitrio: WA 18: 607). Para los católicos, en cambio, la ambigüedad de la Biblia implicaba la necesidad del intérprete autorizado. Precisamente, la función del magisterio católico era defendida por el cardenal Bellarmino a partir de la diferencia jurídica entre la ley y el juez-intérprete: cfr. Bellarmino 1610: vol. I, I. iii, c. 9, 196D-197a.

23 Lutero, De servo arbitrio: WA 18: 609. Este principio se resume en el conocido decreto de la doble predestinación, tan querido a los primeros reformadores: desde toda la eternidad el infierno espera a unos y el reino de Dios a otros: De servo arbitrio: WA 18: 694. La necesidad de inspiración del espíritu está recogida por Calvino en IRC: I, 7, 4. Como indica F. L. Battles en la nota que añade a este pasaje en su edición inglesa, la trascendencia de esta doctrina es tal que se incorpora al Catecismo ginebrino de 1545 (14: 91; 18: 113). La Confesión de Westminster recoge también su influencia (1.5). universales y no todo el mundo recibe. Y Lutero reconocía una capacidad que permitía juzgar los dogmas no sólo para nosotros mismos, sino para los demás. Es en esta facultad en la que se asienta el ministerio de la Palabra. Se trata de una función pública que Calvino ampliará para dar forma a una Iglesia institucional, transformándola en un oficio - dependiente de una vocación divina - que está en manos de los predicadores:

Mas cuando quiso Dios ordenar y edificar su Iglesia de una forma más visible, determinó que su Palabra fuese consignada por escrito, para que los sacerdotes tomasen de ella lo que habían de enseñar al pueblo, y que toda la doctrina fuese regulada conforme a esta regla. ${ }^{24}$

De modo que la vía del examen no remite simplemente a la adecuación personal del creyente al texto sagrado, sino que implica una dimensión supraindividual y, de nuevo mediadora, donde no solo es importante quien interpreta sino cómo se haga. De ahí que Calvino señale que existen unas reglas básicas hermenéuticas que deben aplicarse si se pretende encontrar inspiración moral en la Biblia. ${ }^{25}$ En primer lugar, hay que comprender que las normas morales que vemos recogidas en la Escritura remiten no solo a los actos externos - caso de la ley humana- sino también a los internos. Como ejemplo de dicha regla, el reformador recuerda que cuando la Ley prohíbe la fornicación, el hurto o el homicidio, prohíbe de igual modo la concupiscencia, la ira, el odio, el deseo de lo ajeno, el engaño... Por tanto, apela a la conciencia del fiel y exige que se repriman las intenciones y los pensamientos contrarios a la Voluntad divina. ${ }^{26}$ La segunda regla hermenéutica señala la necesidad de rebasar el sentido literal de la norma para poder comprender lo que ésta exige en toda su amplitud: los preceptos divinos no solo señalan como obligatorio lo recogido explícitamente en ellos, sino que prohíben lo contrario y viceversa. Hay que interpretar las normas morales como sinécdoques, tomando la parte por el todo, puesto que la Ley no requiere de nosotros solamente la abstención del mal, sino que exige una conducta virtuosa: «Si esto agrada a Dios, lo contrario le desagradará; si esto disgusta a Dios, lo contrario le gustará. Si manda esto, prohíbe lo contrario; si prohíbe tal cosa, manda la opuesta». ${ }^{27}$ La tercera regla hermenéutica es la más sustancial puesto que consiste en ver en la Ley la articulación de las dos Tablas, las cuales resumen de modo ejemplar las obligaciones éticas del cristiano: la primera Tabla se refiere a la obligación de adorar a Dios con piedad (pietas) -la religio-, y la segunda apela a la caridad (aequitas), en cuanto que manda amar al prójimo sinceramente. $Y$ lo más importante: la relación entre las dos Tablas es de subordinación, ya que la hermenéutica calviniana, siguiendo

${ }^{24}$ Cfr. Calvino IRC: IV, 8, 6. En el mismo sentido puede leerse a Lutero: De servo arbitrio: WA 18: 653.

25 IRC: II, 8, 6-11. Un análisis de estas reglas puede verse en Hesselink 1992: 112 y ss.; asimismo, Fuchs 1986: 46 y ss.

26 IRC: II, 8, 6.

27 IRC: II, 8, 8. Esta regla tiene unas virtualidades infinitas cuando uno se asoma a un texto como el bíblico, plagado de ambigüedades, prohibiciones y mandatos. El uso que Calvino le da es innumerable: $c f r$. Com. Gen. 1, 26 (CO 23: 25-27), Com. Ps. 14, 4, 8 (CO 31: 138-39), Com. Ps. 81, 1 (CO 31: 759-60), Com. I Cor. 1, 2 (CO 49: 305-32), Com. I Thess. 4, 11 (CO 52: 163-64). CO: Calvin 1863-1900. 
a Agustín, señala que se debe entender la religión como el fundamento de toda justicia. ${ }^{28}$ Esta regla tiene enormes implicaciones en la doctrina política del reformador por cuanto si sólo podemos pensar en construir una sociedad justa y ordenada cuando previamente está resuelta la obediencia a Dios, la ley humana se ve subordinada a la divina si quiere ser llamada de algún modo justa:

Sería tan inútil pretender que hubiese justicia sin religión, como querer hacer que un monstruoso cuerpo sin cabeza fuera hermoso. Porque, a decir verdad, la religión no solamente dirige [est le chef] la justicia y la virtud sino que las anima, como si fuera su alma. Los hombres jamás acatarán la justicia y el amor sin el temor de Dios. [...] Por ello, en la Primera Tabla el Señor nos instruye en la piedad y la religión, para honrar su Majestad. En la Segunda, nos manda organizarnos en sociedades humanas por la obediencia que le debemos. ${ }^{29}$

Como vemos, Calvino no defendía el acercamiento individual y espontáneo a los textos bíblicos, sino un acceso rigurosamente pautado, regulado por unos principios hermenéuticos que podían no ser absolutamente fiables, pero que tampoco permitían una lectura personal o arbitraria. $Y$ en dicha interpretación se debían poner los deberes divinos siempre por encima de los civiles. Más aún, no es la lectura sino la escucha de la Palabra lo que incita al arrepentimiento y favorece la aceptación posterior en la comunidad. De esta obligación, el cristiano nunca está exento. Más aún si pensamos, como señala Monter, que la lectura de la Escritura en las casas particulares era menos común de lo que uno imagina, puesto que la posesión de una Biblia con el texto íntegro era cosa aún rara en el siglo XVI. ${ }^{30}$ La instrucción religiosa continuaba, por tanto, siendo tarea del predicador. ${ }^{31}$

Como vemos, el sentido de la hermenéutica bíblica no era otro que el de suplir lo oscuro por lo evidente y, por lo tanto, permitir el relevo del conocimiento imperfecto de la Voluntad de Dios que ofrece la conciencia, por el conocimiento explícito que ofrece el texto escrito. Ahora bien, la vinculación entre hermenéutica bíblica y oficio pastoral no impidió disputas sobre cómo interpretarla, y reveló que la Escritura no es ni mucho menos un relato sin contradicciones, ni de fácil lectura. La controversia erudita sobre los textos bíblicos muestra contradicciones serias en los escritos aceptados $y$, tan solo un siglo después, la vinculación entre verdad religiosa y Escritura no resultará en absoluto evidente entre los propios protestantes.

28 Fue Lactancio el primero en negar que los romanos conocieran la verdadera justicia a causa de su desconocimiento del verdadero Dios (Lactancio, Divinae institutiones VI, 9,7). Tras sus pasos, Agustín afirmaba que solo estaba presente la verdadera justicia allí donde se vinculaba ésta a la moral cristiana: «En conclusión, donde no existe esta justicia no existe tampoco la congregación de hombres fundada sobre derechos reconocidos y comunidad de intereses. $Y$ si esto no existe, no existe el pueblo, si es que es verdadera la definición dada de pueblo. Por consiguiente, no existe tampoco república, porque donde no hay pueblo, no hay cosa del pueblo» (De civitate Dei XIX, 23, 5).

29 IRC: II, 8, 11. Traducción nuestra.

30 Cfr. Eisenstein 2005. Agradezco a F. Martínez Mesa la referencia. Cfr. Monter 1986: 284.

31 Por otra parte, los sermones no siempre eran comprendidos puesto que la gente no tenía suficiente instrucción o, simplemente, no conseguía escuchar las voces de los predicadores (RCP: I, 150 [6 de enero de 1553]). Sobre la dificultad de comprensión de los sermones por los ginebrinos cfr. Lambert 1998: 361 y ss.

\section{LA HERMENÉUTICA DEL GUSTO: BAYLE}

Bayle se inició en exégesis durante su estancia en Ginebra (1670), aunque sólo fue a partir del 1675 cuando se encuentra en situación de seguir los desarrollos de la crítica filológica, a través de Justel ${ }^{32}$, muy cercana a Richard Simon. Para Simon, aunque la Biblia puede ser considerada Palabra de Dios, también posee los caracteres propios de un libro humano escrito por una pluralidad de autores diferentes, con estilos distintos y compuesta a lo largo de diversas épocas. Bayle mismo resume (y asume) esta posición en sus textos. ${ }^{33}$ En efecto, según el filósofo de Rotterdam, todas las iglesias cristianas aceptan el hecho de que la Escritura no se interpreta por sí misma, señalan oscuridades en el texto y construyen sus diferentes dogmáticas en función de la heterogeneidad de estas interpretaciones. ${ }^{34}$ La discusión sobre cómo interpretar el dogma de la Eucaristía es un ejemplo claro de hasta qué punto el texto sagrado no sirve para dilucidar la verdad religiosa. ¿Cómo interpretar el sentido de las palabras de Jesucristo "este es mi Cuerpo»? ¿Se trata de un sentido literal o figurado? Se han hecho correr ríos de tinta entre las distintas iglesias cristianas para defender una u otra postura y, con ellos, según, Bayle, hemos visto surgir el caos. ${ }^{35}$ Por esa razón, sostiene que el relato bíblico está plagado de contradicciones y errores en el dominio de la física, de la astronomía, de la historia... Errores que no son únicamente consecuencia del trabajo de los copistas, sino confusiones derivadas del contenido mismo al que aluden los textos. Por esa razón, la Escritura no puede ser referente de la verdad revelada, ni por su oscuridad, ni por el tipo de certezas que procura. Las certezas de la fe, avaladas por el principio de autoridad - lo que Dios ha dicho o hecho- o por la hermenéutica de la Escritura, no permiten conocer la verdad religiosa, puesto que carecen de la fuerza de la constatación empírica o racional que presupone la metafísica y la geometría.

Pero, ¿y la conciencia? Para la tradición reformada, la forma privilegiada de acceder al conocimiento religioso siempre ha sido la conciencia. ${ }^{36}$ Pero la regla que sigue la conciencia es la persuasión, no implica regla objetiva alguna. De ahí que las verdades a las que la conciencia accede sean definidas como relativas o putativas. Y es, precisamente, a este campo de verdades putativas, de certezas subjetivas, al

32 Bayle alude a Henri Justel (1620-1693) en numerosas ocasiones en Les Nouvelles de la République des Lettres (NRL) durante el año 1684, como por ejemplo: NRL Mars 1684: VI, OD I, 16. En este trabajo, todas las obras de Bayle serán citadas por la edición electrónica de las obras completas de Bayle (2012) a cargo de A. McKenna y G. Mori. Esta edición reproduce la comúnmente citada por los especialistas: Husson, P. et al. 1727-1731. CEuvres diverses de $M^{r}$ Pierre Bayle, professeur en philosophie et en histoire à Rotterdam. La Haye. 4 vols. Se citará la obra en cuestión y, a continuación, el volumen y la página que ocupa en las oeuvres diverses (OD).

33 NRL décembre 1686, VII, OD I, 717-718.

34 CP II, I, OD II, 396.

35 CP II, VII, OD II, 421.

36 Es cierto que esta conciencia requiere la inspiración del Espíritu Santo, como hemos visto que defiende Calvino, pero para Bayle esta inspiración divina es igualmente complicada de probar. No entraremos en este debate en este momento, pues se trata de discusiones teológicas que nos alejan del argumento principal del texto. Puede leerse: Labrousse 1964: 316-345 (capítulo dedicado a la exégesis). 
que remite la dogmática religiosa, repleta de contradicciones racionales, y carente de cualquier prueba empírica que sirva para sustentar sus afirmaciones ${ }^{37}$ :

Preguntaría encantado a quienes estén dispuestos a responderme, si no es cierto que quien le da a la Escritura el sentido que tiene, lo hace no porque ese sentido sea verdadero sino porque él lo cree verdadero, y que estaría convencido de disgustar a Dios si oyera la Escritura de otra forma. No creo que ni el mejor intérprete de la Escritura sea capaz de nada más que de eso. ${ }^{38}$

Por lo tanto, el fiel acepta las afirmaciones religiosas porque la conciencia se las muestra de modo convincente, no porque pueda justificar objetivamente su verdad. Pero, si eso es así, estamos ante cuestiones tan poco objetivas como el gusto. De ahí que la ortodoxia y la heterodoxia pierdan su sentido, ya que no hay forma de discernir o juzgar en cuestión de gustos. ${ }^{39}$ Pero esto significa aniquilar de raíz la validez de cualquier hermenéutica, pues imposibilita conocer cuál fue la intención o enseñanza que los autores bíblicos quisieron transmitirnos. De ese modo, la creencia religiosa se vuelve algo privado, subjetivo e imposible de analizar con regla alguna..$^{40}$ La razón de esta hermenéutica radicalmente subjetiva está en la epistemología escéptica bayleana, que afirma que todos, ortodoxos y heterodoxos, están igualmente sujetos a la universalidad de los sesgos, lo que implica que nuestras creencias religiosas dependen de la educación que nos proporcionan nuestros padres; del contexto en el nacemos; del peso de nuestro temperamento natural en nuestras decisiones; y del influjo de las pasiones en nuestras certidumbres. ${ }^{41}$ Estos sesgos conllevan que la responsabilidad religiosa debe medirse en función de criterios no objetivos: la sinceridad y buena fe con que uno cree que lo que profesa es verdad, es suficiente en religión porque a lo que Dios obliga es a respetar la verdad, siempre que la conozcamos, puesto que es de todo punto imposible actuar conforme a una verdad que no se conoce, o bien dejar de hacerlo cuando el error asume la forma de verdad y la conciencia la acepta como tal. ${ }^{42}$ Ahora bien, aceptar esto supone que la conciencia errónea invencible se vuelva indistinguible de la conciencia supuestamente veraz. ${ }^{43} \mathrm{~A}$ la

37 CP II, X, OD II, 438. La certeza moral remite a lo probable, aunque no sea lo racional u objetivo. Bayle, en sus últimos escritos, termina negando que se necesite buscar certeza moral, la certeza subjetiva es más que suficiente cuando hablamos de creencias religiosas.

$38 \mathrm{CP}$ II, X, OD II, 442-443.

39 «Il suffit aussi que la conscience d'un chacun lui montre, non pas ce que les objets sont en eux-mêmes, mais leur nature respective, leur vérité putative. Chacun discernera par ce moïen sa nourriture. II faudra qu'il tâche de discerner la meilleure, et qu'il y emploïe tous ses soins; mais si lui étant présentée, sa conscience ne s'en accommode pas, et se trouve sans aucun goût pour elle, et avec un grand goût pour une autre chose, à la bonne heure; il faudra prendre ce dernier parti» (CP II, X, OD II, 441).

40 La subjetivización de la conciencia encuentra su asidero en el concepto de conciencia errónea invencible, elemento fundamental de su doctrina de la tolerancia. Hemos desarrollado ampliamente este problema en García-Alonso 2015: 35-56.

41 Sobre la vinculación de epistemología escéptica y doctrina de la tolerancia: Laursen 2011: 131-144. Asimismo, ibídem 2008: 121-130.

42 NLCG I, Lettre IX, OD II, 219. NLCG: Nouvelles lettres de l'auteur de la Critique générale de l'Histoire du Calvinisme (1685). Bahr 2001: 59-80.

43 Un amplio estudio sobre los derechos de la conciencia en Bayle en Kilcullen 1998: 54-105. Asimismo, Laursen 2001: 211-228. McKenna 2012: 85-100. hora de juzgar la creencia religiosa, por tanto, lo que ha de ser tenido en cuenta es la obligación formal del fiel de seguir su conciencia y no el contenido material a la que ésta se adhiere. ${ }^{44}$ De nuevo, la consecuencia más evidente será que ortodoxia y heterodoxia pierdan su sentido y, con ello, que las persecuciones en nombre de la fe pierdan su legitimidad.

Como hemos visto, en menos de un siglo, se pasa de articular reglas hermenéuticas objetivas para que el pastor pueda enseñar la Voluntad de Dios a sus fieles, a la rotunda negación de la viabilidad de regla alguna para acceder a la verdad religiosa. ${ }^{45} \mathrm{Si}$ el objetivo de Calvino había sido establecer una nueva ortodoxia, basada en normas diferentes a las estipuladas por el magisterio católico, el propósito de Bayle fue el de desdibujar la diferencia entre ortodoxia y heterodoxia, con el fin de asentar en base firme su doctrina de la libertad de conciencia. Una libertad que se afirmó en discusión con la tradición eclesiológica reformada y sus pilares dogmáticos fundamentales. Nos queda, sin embargo, por evaluar si la libertad de conciencia conlleva una defensa de la libertad política. El análisis de la propuesta política de Bayle nos mostrará que estos conceptos no tienen por qué ir de la mano.

\section{LA SOBERANÍA POPULAR O LA DISOLUCIÓN DE LA POLÍTICA: BAYLE}

Ciertamente, la libertad de conciencia bayleana está anclada en los derechos de la conciencia errante invencible y, por lo tanto, en la aceptación de que no hay más verdad religiosa que la que es aceptada como tal por el creyente (la que le muestra como verdadera su conciencia), como hemos visto. ¿Defiende la misma tesis en política, esto es, que no hay más orden político que el que uno acepta personalmente? En absoluto. Según Bayle, la herejía es soportable mientras no implique desórdenes políticos, pero suponer soberanía a todo individuo implica dotarle de un derecho que siempre ocasiona problemas de orden público:

Antes se os permitiría tratar de idólatra a la religión el rey que decir que él no está por encima del pueblo. Al margen del grado de su piedad, los monarcas padecen mejor las herejías que afectan a la religión que las que atañen a su autoridad o su persona. $Y$ es igualmente cierto que son esas las que más perturban la paz pública. ${ }^{46}$

Sin embargo, el adversario del filósofo de Rotterdam, el también calvinista Pierre Jurieu, fue uno de los defensores de las doctrinas de la soberanía popular y de la teoría del pacto más tenaces del siglo XVII. Aunque, a decir de Bayle, sostuvo estas doctrinas únicamente con el fin de amparar la sedición protestante contra el rey católico James II e imponer la religión protestante en Inglaterra, tras la Revolución Gloriosa. Por esa razón, Bayle le acusa de estar entre los escritores que, a la hora de enfrentarse a sacerdotes, papas y jesuitas, defienden la sacralidad de la institución monárquica, pero que adoptan la doctrina de la soberanía

44 CP I-V, OD II, 379

45 Sobre el problema de la hermenéutica bíblica en el siglo XVII puede leerse: Laplanche 1986.

46 Avis, OD II, 609. Avis: Avis aux Réfugiés (1690). 
popular cuando conviene a su causa religiosa. ${ }^{47} \mathrm{El}$ filósofo de Rotterdam, sin embargo, considera que la función de estas doctrinas no es otra que abrir una brecha en el poder político, facilitando la insumisión y ofreciendo oxígeno a la pretensión del clero de controlar a los gobernantes, al enfrentarles al pueblo. Se trata de doctrinas perniciosas ,no solo a la vista de las consecuencias que provocan sino que son, además, incongruentes en sus principios. Y es que, para Bayle, un contrato no supone una soberanía popular completamente alienada, por lo que no permite evitar el problema de la crisis de autoridad a la que se enfrentan los reinos del siglo XVII. ${ }^{48} \mathrm{~A}$ pesar de que el pueblo delegue la mayor parte de sus poderes en las manos de procuradores o plenipotenciarios, siempre le cabe la posibilidad de mantener algún grado de soberanía, en función de la cual, se puede reservar un último derecho de inspección de la conducta de las autoridades. La soberanía popular presupone que los soberanos y los súbditos se obliguen mutuamente, mediando en ello un contrato, de tal manera que, si los magistrados no cumplen con sus promesas, los súbditos pueden sentirse libres de la sujeción que les deben, al tener derecho a juzgar lo que se les exige y a decidir si es conforme al bien público y a sus privilegios particulares, sin que se les pueda comprometer en nada que sea perjudicial a su causa: salus populi suprema lex esto. ${ }^{49}$ De ese modo tan simple, según Bayle, queda justificada cualquier sedición..$^{50}$ Aún más, si los parlamentos, los Estados Generales, o los éforos son los últimos custodios del pueblo ¿quién vigilará su conducta - sed quis custodiet ipsos custodes-? ¿Cómo justificar que libremente se sometan a la voluntad de un parlamento y no a la de un monarca?

Con el fin de evitar la crisis de autoridad que hemos descrito, el filósofo de Rotterdam defenderá que no debe haber un poder legislativo al margen del ejecutivo, de ahí su oposición al parlamentarismo. Solo cuando monarca y parlamento actúan de modo unánime, como uno solo - como soberano-, tendrá sentido su acción. Si se considera que el parlamento está para controlar o vetar la acción legislativa del monarca, entonces estamos ante una soberanía dividida y, en su opinión, incapaz. ${ }^{51}$ Incluso defiende que la intromisión del parlamento puede ser nefasta en ocasiones, pues entiende que la razón principal del fracaso del Edicto de Nantes fue la injerencia de los parlamentos en la legislación político-religiosa de Francia. ${ }^{52}$ Por todo ello, el concepto mismo de soberanía debe implicar no solo una única instancia ejecutiva y legislativa sino que también debe poseer en exclusividad el poder

47 Avis, OD II, 592

48 Avis, OD II, 594.

49 Ya en tiempos de Calvino, autores como John Knox (1514-1572), Christopher Goodman (1520-1603), o George Buchanan (1506-1582) los tres citados en el Avis- defendían que, si los soberanos actúan contra la verdadera religión, sus súbditos pueden desligarse del juramento de fidelidad que le prestaron (Avis, OD II, 606-607). En el mismo sentido: DHC: Dictionnaire Historique et Critique (Bayle 1750) se cita según la quinta edición de P. Brunel.

50 Según Bayle, aunque no han sido sus inventores, fueron los jesuitas los que han conseguido llevar más lejos las consecuencias de esta doctrina política (DHC Loyola S).

51 RQP IV-III, OD III, 1018. RQP: Réponse aux question d'un Provicial (1703-1707).

52 DHC Hôpital, remarque K; DHC Cameron L. RQP IV, 3, OD III, 1017. de enjuiciar. ${ }^{53}$ Este derecho no solo supone la capacidad de juzgar la conducta de los súbditos en función de la legislación vigente, sino que implica que ningún particular tiene derecho a iniciar guerra alguna, civil o interestatal. El Derecho de gentes prohíbe que se perpetre coacción alguna por parte de aquellos que carecen de soberanía o, lo que es lo mismo, deniega todo poder de coacción a los individuos en tanto particulares. ${ }^{54} \mathrm{El}$ derecho de vida y muerte pertenece únicamente al soberano. ${ }^{55}$

Por tanto, si Bayle supone que el buen funcionamiento del cuerpo político requiere que se constituya un único y último juez con autoridad para imponer penas y dar leyes, es porque los teóricos de la soberanía, como Hobbes o Bodino, han padecido los resultados de las revueltas en forma de guerras civiles y atentados populares contra la monarquía, y han comprendido que la soberanía popular aboca a la anarquía y la disolución social. ${ }^{56}$ Esta soberanía indivisible que estamos describiendo coincide, en lo esencial, con la descrita en la obra de Elie Merlat, Traité du pouvoir absolu des Souverains, que él mismo ayuda a publicar y reseña en $1685 . .^{57}$ Pero, a diferencia de Hobbes, Bodino o del propio Merlat, para Bayle, el titular de la soberanía puede ser una o varias personas, organizarse políticamente como una república o como una monarquía. Lo fundamental, como hemos dicho, es que sea indivisible, que reúna poder ejecutivo, legislativo y penal en un mismo titular. De modo que soberanía indivisible no es sinónimo de absolutismo monárquico. Bayle entiende que la soberanía puede estar representada por un monarca o por una élite oligárquica, pero en ningún momento acepta que pueda ser democrática. A ojos del filósofo de Rotterdam, la democracia y la soberanía popular son una misma cosa: la propuesta de disolución de la política. ${ }^{58}$ Ahora bien, esta soberanía no es ilimitada, tiene un marco de acción definido y es exclusivamente político. La conciencia no se cuenta entre las prerrogativas del soberano, por lo que toda ley contra la conciencia es nula: «(...) los reyes no han recibido ni de Dios ni de los hombres el poder de obligar a sus súbditos a que actúen contra su conciencia». ${ }^{59}$

Ya hemos visto que Bayle puede contarse difícilmente entre los antecedentes del liberalismo político. Pero ¿y Calvino?

\section{LA INEFICACIA POLÍTICA DEL PUEBLO: CALVINO}

La discusión que ocupa principalmente a los teólogos durante los siglos XIII-XVI no es la del mejor régimen posible o la doctrina de la soberanía, sino la del origen directo o mediado de la potestad divina. $Y$, en este sentido, Calvino

53 Avis, OD II, 613.

54 Avis, OD II, 613

55 Avis, OD II, 614.

56 Avis, OD II, 594. Así lo reconoce en su artículo Bodin Q. Según Bayle, Hobbes, a su vez, escribe sobre las repúblicas para demostrar, a contrario, que las monarquías son mucho más estables y preferibles: DHC Hobbes C.

57 Es la crítica a la soberanía popular y al derecho de resistencia lo que a Bayle le interesa de las tesis de Merlat, no su fundamento teológico (NRL, VII agosto 1685, OD I, 353-354).

58 Hemos desarrollado este debate en García-Alonso 2016: 331-344.

$59 \mathrm{CPI}, \mathrm{VI}, \mathrm{OD}$ II, 384. 
defenderá que toda autoridad recibe su poder directamente de Dios. Es por eso que las autoridades políticas pueden ser llamadas vicarios y lugartenientes divinos. Dirá incluso que su función es sagrada (tressacrée $)^{60}$ y que la política no es un efecto del pecado, sino voluntad de la Providencia. ${ }^{61}$ Más aún, el papel fundamental de los magistrados será llevar adelante el gobierno providente de Dios en la tierra, puesto que son sus instrumentos, sus manos. Es por ello que pueden y deben dictar leyes (poder legislativo), promulgar edictos (poder ejecutivo) e imponer justicia (poder judicial). ${ }^{62}$ ¿Y el pueblo, qué lugar tiene en su doctrina política? En palabras de Calvino: «El primer deber de los súbditos para con sus superiores consiste en tener en alta estima su oficio de modo que, entendiendo que se trata de un mandato de Dios, [deben] tratarlos con honor y reverencia por ser Sus lugartenientes y vicarios ${ }^{63}{ }^{63}$ Es cierto que sostiene que Dios se sirve del pueblo para elegir a las autoridades públicas, pero su función es meramente instrumental, se limitan a reconocer la autoridad elegida por Dios y no a instituirla. ${ }^{64}$

La obligación de toda persona privada en relación a sus gobernantes es, por tanto, la de obedecer, lo que se justifica apelando al mandato paulino expuesto en Rom. 13, e invocando el quinto mandamiento sobre el respeto filial. ${ }^{65}$ No importa, por tanto, si la autoridad es familiar, doméstica, política o eclesial: la obligación de respetar su dominio permanece incólume y debe cumplirse no por miedo al superior, sino por la obediencia debida a Dios. ${ }^{66} \mathrm{Y}$ por eso mismo, nadie puede resistir a las autoridades sin resistir al mismo tiempo a Dios. En consecuencia, no resulta extraño que Calvino defienda la imposibilidad para una persona privada de enfrentarse o resistir a la autoridad pública. ${ }^{67}$ Lo cual no obsta, desde luego, para que el pueblo y la magistratura tengan obligaciones mutuas, pero dicha obligación no depende de un contrato: la obediencia del pueblo a las autoridades políticas es una obediencia mediada por la obediencia debida a la ley de Dios, del mismo modo que el buen gobierno del magistrado es un deber contraído con el pueblo por imposición divina. Por ello, si el pueblo es víctima de un mal magistrado, sólo le queda rezar y aceptar su gobierno como castigo divino a sus pecados. ${ }^{68}$ Ahora bien, si el gobernante se vuelve contra la ley divina, queda en cuestión su propia legitimidad. ${ }^{69}$ No obstante, la resistencia contra el gobernante impío no será particular o popular, sino siempre institucional, encabezada por autoridades públicas en el legítimo

\footnotetext{
60 IRC: IV, 20, 4.

${ }_{61}$ IRC: IV, 20, 4; 20, 6-7; 20, 9, respectivamente. Las mismas expresiones son usadas por Lutero: el magistrado es llamado lugarteniente de Dios, su oficio es descrito como divino, padre de la comunidad, imagen y figura del dominio de Cristo, pío jurista... Sobre estas y otras figuras y su localización en el corpus luterano puede verse Witte 2007: 111 y ss. García-Alonso 2005: 281-301.

62 IRC: IV, 20, 6.

${ }^{63}$ IRC: IV, 20, 22. Puede verse nuestra traducción del capítulo IV en Calvino 2016: 53.

${ }_{64}$ El pueblo aprobaba o rechazaba propuestas que venían de fuera, nunca se trató de una decisión democrática. Es en este sentido se puede llamar republicano a Calvino, siempre que entendamos que no defiende un republicanismo democrático. Una discusión sobre el concepto de republicanismo clásico en Coleman 2005: 27-47.

65 Sobre el quinto mandamiento: IRC: II, 8, 36.

66 IRC: IV, 20, 22.

67 IRC: IV, 20, 23.

68 IRC: IV, 20, 29. Traducción en Calvino 2016: 72.

69 IRC: IV, 20, 32.
}

ejercicio de sus funciones. A un mandatario impío investido de autoridad divina sólo se puede oponer otro de igual investidura, por lo que el ejercicio de la resistencia corresponderá exclusivamente a otra autoridad: los magistrados inferiores:

Pues si hubiese en estos momentos magistrados instituidos para defender al pueblo, para refrenar la excesiva avaricia e inmoralidad de los reyes - como antiguamente los lacedemonios tenían a los llamados éforos, los romanos a sus tribunos de la plebe, los atenienses sus demarcas, y como acaso hoy tenga cada reino a los tres estados cuando son convocados-, [repito] a quienes fueran instituidos en tal oficio, no les prohibiría que se opusieran y resistieran al abuso o crueldad de los reyes, conforme [exige] el deber de su oficio. Más aún, si viendo que los reyes maltratan desproporcionadamente a su pobre pueblo lo encubren, consideraría que se les debe acusar de perjurio por tal encubrimiento, con el que traicionarían vilmente la libertad del pueblo, de la que saben que han sido instituidos tutores por voluntad de Dios. ${ }^{70}$

No hay que olvidar que Calvino es jurista de modo que, al afirmar que los únicos capacitados para resistir serían los tutores, estaría aceptando la incapacidad política del pueblo puesto que, según romanistas y canonistas, la tutoría romana fue clásicamente interpretada desde la teoría política paulina, la cual transformaba al magistrado en tutor regni, es decir, en protector o tutor de un superior sobre un inferior o, en términos jurídicos romanos, de un mayor sobre un menor. ${ }^{71}$

\section{A MODO DE CONCLUSIÓN}

Hemos visto que Calvino no defiende la libertad de conciencia, ni la autonomía hermenéutica de la Biblia, y tampoco es partidario de la libertad política. Puede que no sea demasiado extraño si pensamos que se trataba de un hombre de Iglesia, decidido a construir una vía institucional alternativa al catolicismo pues, en esa tarea, necesitaba del apoyo del brazo secular. No olvidemos, sin embargo, que nunca reconoció más potestad coactiva a la Iglesia que la de expulsar a sus miembros temporalmente de la comunidad eclesial. En el Estado calvinista, solo el poder civil detenta el monopolio de la violencia. ${ }^{72}$ De ahí que la discusión posterior entre lealtad y resistencia al régimen político fuera tan complicada. Los hugonotes franceses no dejaron nunca de intentar articular su obediencia política y religiosa, por muy complicada que fuera ésta.

70 IRC: IV, 20, 31.

71 Cfr. Ullmann 1981: 499-501.

72 Nos sorprende enormemente seguir leyendo hoy día en España a historiadores que, como Ma Elvira Roca Barea, dicen que Calvino quemó a 500 herejes («Los españoles tenemos un problema de autoestima», El País, 27 de febrero de 2017: http://cultura.elpais. com/cultura/2017/02/27/actualidad/1488186245_628784.html). Las sentencias de muerte fueron siempre prerrogativa exclusiva del poder civil, nunca eclesial y la iglesia solo tenía a su alcance medios espirituales de coacción (ningún castigo corporal). Otra cuestión es la coordinación efectiva que hubiera entre ambos, que es innegable. Hay más de 21 volúmenes de registros manuscritos en los Archivos del Estado de Ginebra que remiten a la actividad del Consistorio en tiempos de Calvino. El trabajo de edición comenzó con la dirección de Robert Kingdon en 1996 . El último volumen publicado en 2014. Registres du Consistoire de Genève au temps de Calvin. Tome VIII, Watt, I. M. y Watt J. R. (eds). Ginebra: Droz. Sobre el consistorio puede leerse Lambert 1998. 
Asimismo, tampoco el heterodoxo Bayle vincula libertad de conciencia e interpretación bíblica subjetiva y libertad política. Para Bayle nada más absurdo que defender la soberanía popular puesto que, como hemos visto, abre las puertas a la sedición y a la influencia del clero sobre el pueblo. Su alternativa fue la de una soberanía política fuerte, con toda la concentración posible de poder, en sentido contrario a lo defendido por Calvino. De ahí que probar la continuidad entre Calvino y Bayle no resulte menos complicado en el ámbito político que en el religioso, puesto que la doctrina de la libertad de conciencia defendida por el filósofo de Rotterdam solo se entiende en oposición al calvinismo ortodoxo de su época, más cercano a las propuestas eclesiales y hermenéuticas de Calvino.

Evidentemente, en nuestro artículo solo hemos discutido dos casos que, aunque representativos de la ortodoxia y heterodoxia calvinista, no sirven para zanjar el amplio debate sobre la aportación de la Reforma a la doctrina liberal. ${ }^{73}$ Tampoco lo hemos pretendido. Lo que queríamos discutir era la continuidad indiscutible que se postula entre hermenéutica bíblica, libertad de conciencia y libertad política, que hemos descrito en términos de leyenda o mito. La influencia de la Reforma en la modernidad ha sido compleja y de ningún modo se puede vincular a un único movimiento o doctrina política. La aportación de Lutero fue muy diferente de la de Calvino; la de Locke o Thomasius de la de Bayle; la de Leibniz distinta de la de Hume o Rousseau, como vemos en este volumen. ¿Tiene sentido simplificarlas y forzarlas a entrar en una matriz en la que deberían, a su pesar, ser comprendidas únicamente como antecedentes de un pensamiento posterior? Las tradiciones son más complejas y heterogéneas de lo que solemos reconocer y cuando se simplifican se tiende a describirlas bajo la luz de una uniformidad ficticia; se dotan de una coherencia que implica eliminar la diversidad interna de que gozan; se abstraen sus contextos y se liman las controversias internas... Y, al hacerlo, se aleja a sus protagonistas de la realidad histórica en que escribieron; incluso se dejan de leer algunos de sus textos por no estar articulados al modo de sistemas. No hay que olvidar que mucha historiografía filosófica descarta del canon a autores como Bayle, Pufendorf o Thomasius por esa razón. ${ }^{74}$ Sin embargo, fueron estos autores los que contribuyeron enormemente al discurrir de doctrinas filosóficas y políticas tan importantes como la tolerancia, la soberanía popular o el derecho subjetivo. Ideas y doctrinas que surgen en tensión y discusión, tanto hacia dentro como hacia fuera de la propia tradición a la que pertenecen por nacimiento sus autores. Dar cuenta de estas modulaciones, conflicto y diversidad debería ser tarea del historiador de las ideas y del filósofo político-moral, y no la de reducir la complejidad a tópicos, sean estos negros o dorados. Estamos convencidos de que, con ello, la aportación de la Reforma a nuestra modernidad política adquirirá el interés y la dimensión que merece.

73 Evidentemente, el calvinismo es muy variado, como muestran los trabajos recientes de Ramis 2015; y Adrián Lara 2015.

74 Estamos de acuerdo con Haakonsen cuando señala que la comprensión de la discusión filosófica centrada en sistemas de fundamentación gnoseológica es una reconstrucción del s. XIX que proyecta su propia forma de comprender la filosofía en el pasado, lo que no permite comprender bien las discusiones de siglos anteriores, donde los debates eran primariamente morales, religiosos o políticos. Haakonssen 2006: 3-25.

\section{BibLIOgRAFíA}

Adrián Lara, L. 2015. Dialéctica y calvinismo. Madrid: CEPC.

Bahr, F. 2001. «El Commentaire philosophique de Pierre Bayle: 'Dios no quiere que conozcamos con certeza'». Tópicos 9: 59-80.

Bayle, P. 1750. Dictionnaire Historique et Critique. Amsterdam, Leyde, La Haye, Utrecht. 4 vols. [P. Brunel (ed.)].

Bayle, P. 2012. Corpus Bayle Oeuvres Complètes. Paris: Garnier electronique. [A. McKenna y G. Mori (eds.)].

Bejan, T. 2011. "The Bond of Civility: Roger Williams on Toleration and its Limits». History of European Ideas 37: 409-420.

Bellarmino, R. 1610. Disputationes de controversiis christianae fidei adversus huius temporis haereticos. Lyon.

Calvin, J. 1863-1900. Joannes Calvini opera quae supersunt omnia. Braunschweig. [G. Baum, E. Cunitz y E. Reuss (eds)]. Edición digital: Calvin, J. 2005. Calvini Opera Database. Apeldoorn: Instituut voor Reformatieonderzoek. [DVD]. [H. J. Selderhuis (ed.)].

Calvin, J. 1957-1963. Institution de la religion chrestienne. París: Vrin. 5 vols. [Edición crítica de J. D. Benoît sobre la versión francesa definitiva de 1560].

Calvino, J. 2016. Calvino. Textos políticos. Madrid: Tecnos. [M. GarcíaAlonso (ed.)].

Castilla, F. y Villaverde, M.a J. 2016. «La leyenda negra: existencia, origen, recepción y reacciones. [Estudio preliminar]», en F. Castilla y M.a J. Villaverde (eds.), La sombra de la leyenda negra: 11-98. Madrid: Tecnos.

Coleman, J. 2005. «El concepto de república. Continuidad mítica y continuidad real». Res Publica 15: 27-47.

Eisenstein, E. 2005. The printing revolution in Early Modern Europe. Cambridge: Cambridge University Press.

Fernández Sebastián, J. 2015. «A Distorting Mirror: The Sixteenth Century in the Historical Imagination of the First Hispanic Liberals». History of European Ideas 41: 166-175.

Fernández Sebastián, J. 2016. “'Los desaciertos de nuestros padres'. Los liberales y la eclosión del llamado 'problema español'», en F. Castilla y M. a J. Villaverde (eds.), La sombra de la leyenda negra: 483-510. Madrid: Tecnos.

Fetscher, I. 1995. La tolerancia. Barcelona: Gedisa.

Fuchs, E. 1986. La morale selon Calvin. París: CERF.

García-Alonso, M. 2005. «Poder, derecho y secularización. Un apunte sobre Lutero». Revista de estudios politicos 129: 281-301.

García-Alonso, M. 2008. La teología política de Calvino. Madrid: Anthropos.

García-Alonso, M. 2015. «Creencia religiosa y conciencia errónea según Pierre Bayle». Anuario Filosófico 48/ 2: 35-56.

García-Alonso, M. 2016. «Bayle's political doctrine: a proposal to articulate tolerance and sovereignty». History of European Ideas 43/4: 331-344. (http://dx.doi.org/10.1080/01916599.2016.1203593).

Gillespie, M. A. 2008. The Theological Origins of Modernity. Chicago: University of Chicago Press.

Ginzo, A. 2000. Protestantismo y filosofía: la recepción de la Reforma en la filosofía alemana. Madrid: Universidad de Alcalá.

Gómez-Heras, J. M. 1986. Religión y Modernidad. La crisis del individualismo religioso: de Lutero a Nietzsche. Córdoba: Publicaciones del Monte de Piedad y Caja de Ahorros de Córdoba.

Haakonssen, K. 2006. «The History of Eighteenth-Century Philosophy: History or Philosophy?», en K. Haaksonssen (ed.), The Cambridge History of Eigteenth-Century Philosophy: 3-25. Cambridge: Cambridge University Press.

Hegel. 1989. Lecciones sobre la filosofía de la historia universal. Madrid: Alianza. [J. Gaos (ed.)].

Hesselink, J. 1992. Calvin's Concept of the Law. Pennsylvania: Pickwick Publications.

Jacob, M. 1991. Living the Enlightenment: Freemasonry and Politics in Eighteenth-Century Europe. New York: Oxford University Press.

Jacob, M. 2003. The Radical Enlightenment. Pantheists, Freemasons and Republicans. Morristown: The Temple Publishers [segunda edición revisada, original 1981].

Jellinek, G. 1980. Teoría General del Estado. Buenos Aires: Albatros. 
Jellinek, G. 2000. Declaración de los derechos del hombre y del ciudadano. México: Universidad Autónoma de México.

Kilcullen, J. 1998. "Bayle on the rights of conscience», en Essays on Arnauld, Bayle, and Toleration: 54-105. Oxford: Clarendon Press.

Labrousse, E. 1964. Pierre Bayle II: Hétérodoxie et rigorisme. Paris: Albin Michel.

Lambert, T. 1998. Preaching, Praying and Policing the Reform in Sixteenth Century Geneva. Madison: University of Wisconsin.

Laplanche, F. 1986. L'Écriture, le sacre et l'Histoire. Érudits et politiques protestants devant la Bible en France au XVIle siècle. AmsterdamMaarsen: APA-Holland University Press.

Laursen, J. C. 2001. "The necessity of conscience and the conscientious persecutor: The paradox of liberty and necessity in Bayle's theory of toleration", en L. Simonutti (ed), Dal necessario al possibile: Determinismo e libertà nel pensiero anglo-holandese del XVII secolo: 211-228. Milan: Angeli.

Laursen, J. C. 2008. «Skepticism, Tyranny and Toleration», en I. Pervova (ed.), Tolerance and intolerance in the Modern Society: the East, the West: 121-130. St Petersburg: St. Petersbourg State University.

Laursen, J. C. 2011. "Skepticism against Reason in Pierre Bayle's Theory of Toleration», en D. Machuca (ed.), Pyrrhonism in Ancient, Modern, and Contemporary Philosophy: 131-144. Springer: Dordrecht.

Lutero. 1983. Luthers Werke Studienausgabe. Berlin: De Gruyter. 4 vols. [O. Clemen (ed.)].
McKenna, A. 2012. "Pierre Bayle: free thought and freedom of conscience». Reformation and Renaissance Review 14/1: 85-100.

Monter, W. 1986. "La Réforme au quotidien», en P. Chaunu (dir.), L'Aventure de la Reforme: 284. París: Hermé

Nussbaum, M. 2008. Liberty of conscience: in defense of America's tradition of religious equality. New York: Basic Books.

Pinty, M. 2012. «Protestantism and progress in the year XII: Charles Villers's Essay on the spirit and influence of Luther's Reformation (1804)». Modern Intellectual History 9/2: 303-329.

Pocock, J. G. A. 1999. Barbarism and Religion, volume 1. The Enlightenments of Edward Gibbon. Cambridge-New York: Cambridge University Press.

Ramis, R. 2015. Petrus Ramus y el Derecho. Madrid: Dykinson.

Sheehan, J. 2005. The Enlightenment Bible: Translation, Scholarship, Culture. Princeton.

Tocqueville, A. 2010. De la démocratie en Amérique. Paris: G.F. Flammarion. [P. Raynaud (ed.)].

Ullmann, W. 1981. "Calvin and the Duty of Guardians to Resist: a further Comment». Journal of Ecclesiastical History 32: 499-501.

Villers, Ch. 1804. Essai sur l'esprit et influence de la réformation de Luther. [Texto electrónico: http://www.chez.com/sdg/, acceso febrero 2017].

Witte, J. 2007. The Reformation of Rights: Law, Religion and Human Rights in Early Modern Calvinism. Cambridge: Cambridge University Press. 